\title{
Short term effects of urban air pollution on respiratory health in Milan, Italy, 1980-89
}

\author{
M A Vigotti, G Rossi, L Bisanti, A Zanobetti, J Schwartz
}

\begin{abstract}
Study objective - To investigate the association between daily urban air pollution and acute effects on respiratory health. Study design - Time series analysis following the procedure defined in the APHEA protocol.

Setting - City of Milan, Italy, from 1980-89. Two air pollutants, total suspended particulates (TSP) and sulphur dioxide $\left(\mathrm{SO}_{2}\right)$, and two health outcomes, deaths and hospital admissions were considered. The last was analysed according to two age groups. Subjects - Daily deaths and general hospital admissions for respiratory causes in residents who died in Milan or were admitted to local hospitals in that city.

Main results - There was an increased risk of respiratory death and of hospital admission associated with increased concentrations of $\mathrm{SO}_{2}$ and TSP. The relative risks were similar for both pollutants, and were higher for respiratory deaths than for hospital admissions. No changes in relation to season were seen in the $\mathrm{SO}_{2}$ effect on respiratory deaths, but there was a suggestion of a higher effect on hospital admissions in the cool months. The seasonal pattern of the TSP effect was inconsistent: for mortality it was higher in the warm period while for hospital admissions it seemed to be higher in the cool months. This last result might be due to chance, although some role could have been played by the hospital admission data on all general admissions for respiratory causes (ICD-9: 460-519) as these are a much less specific end point.

Conclusion - In Milan, a positive association was found between the daily $\mathrm{SO}_{2}$ or TSP concentrations and the number of deaths or hospital admissions for respiratory causes. This confirms results from other European and North American cities.
\end{abstract}

(f Epidemiol Comm Health 1996;50(Suppl 1):S71-S75)

The episodes of very high pollution that occurred in the Meuse Valley in $1930,{ }^{1}$ in Donora, $\mathrm{PA}$ in $1948,{ }^{2}$ and in London in $1952^{3}$ produced clear increases in the number of daily deaths. Since then, studies have reported smaller increases associated with much lower levels of air pollution..$^{4-13}$ Most of these studies have been conducted in North America, but more recently similar analyses have been reported in Europe, ${ }^{14-20}$ South America, ${ }^{21}$ and China. ${ }^{22}$

The principal associations have been reported with airborne particles and with sulphur dioxide $\left(\mathrm{SO}_{2}\right)$. It has generally been difficult to separate the contributions of the two pollutants because of their high correlation within a city. However, an analysis in Santa Clara, California $^{4}$ found an association between daily deaths and an optical measure of airborne particles in a town with essentially no $\mathrm{SO}_{2}$ present. Studies have also been conducted that examine correlations between short term changes in air pollution and hospital admissions for respiratory diseases in North America. ${ }^{23-31}$ This is also less well examined in Europe. ${ }^{32-34}$

The APHEA project, a multicentre study funded by the European Community, has examined these associations in a range of cities across both eastern and western Europe ${ }^{35}$; because these cities represent a range of co-pollutants, and of coincident weather patterns, this study offers the opportunity to examine some issues of potential confounding using cross study comparisons. Milan is one of the few cities in Italy where daily data on air pollutant concentrations and daily death and hospital admission counts have been available for an extended period. A study of the short term effects of air pollution on health in Milan $^{36}$ was started in 1991, with funding from the Italian National Research Council (CNR) and the Electric Power Authority (ENEL). The study joined the APHEA project in 1993. In this paper we report on the results obtained when analysing the short term associations between total suspended particulate matter (TSP) and $\mathrm{SO}_{2}$ on the number of deaths and the number of hospital admissions due to respiratory disease.

Study design and methods

The municipality of Milan had a mean population of 1.5 million inhabitants during the study period. This population decreased slowly from 1981 ( 1.6 million) to 1989 ( 1.45 million). The population age structure showed the typical changes of most western European cities during that period: a reduction in the percentage of children (aged 14 and younger) from $4 \cdot 1 \%$ to $3 \cdot 2 \%$ of the population and an increase in the elderly population (aged 65 and older) from $14 \cdot 1 \%$ to $16 \cdot 2 \%$. The study area included the central urban area; most of the industries are located north of the city itself.

AIR POLLUTION AND METEOROLOGICAL DATA Air pollution data were provided by the interdistrict Defence Network for Health and Protection (PMIP) of Milan. During the years 1980-89 reliable data were available from four monitoring stations. These stations were loc- 
ated in different quadrants of the city, about $100 \mathrm{~m}$ within the Milan ring avenues. They were generally located in school yards. The 24 hour concentrations of TSP were measured by $\beta$ attenuation method and the 24 hour $\mathrm{SO}_{2}$ concentrations by coulometric method. The $\mathrm{SO}_{2}$ mean hourly concentrations were computed from 15 second automatic measures, while the TSP values were acquired at the end of a two hour cycle of measurements. The 24 hour averages were computed if at least $75 \%$ of the measures were available. TSP concentrations were only available for two monitoring locations, and the correlation between their measurements was $0 \cdot 81 . \mathrm{SO}_{2}$ concentrations were available from all four stations, and the correlation among those stations ranged from 0.89 to 0.91 . The correlation between the TSP and $\mathrm{SO}_{2}$ was quite high $(\mathrm{r}=$ $0 \cdot 63$ ). Days with missing values were estimated following the APHEA protocol. ${ }^{30}$ The TSP concentrations showed a slight upward trend during $1980 \mathrm{~s}$, increasing from an average of $132.2 \mu \mathrm{g} / \mathrm{m}^{3}$ in the years $1980-84$ to an average of $142.5 \mu \mathrm{g} / \mathrm{m}^{3}$ in the years $1985-89$. In contrast, $\mathrm{SO}_{2}$ concentrations fell dramatically during the period - from 157 to $87 \mu \mathrm{g} / \mathrm{m}^{3}$. This was mainly because of national and local legislation requiring the use of lower sulphur fuel, the conversion of home heating in about half the residences to natural gas, and the transfer of industries outside of the city.

Daily mean temperature and relative humidity were drawn from the Brera-Dome monitoring station in the centre of the city. During the study period, the temperature ranged from an average of $23.6^{\circ} \mathrm{C}$ (range 11-31) in the summer to $4 \cdot 3^{\circ} \mathrm{C}$ (range -6 to 13 ) in the winter. For relative humidity, the equivalent values were $56 \%$ (range 17-95) in summer and $67 \%$ (range 6-100) in winter. The distribution of pollution concentrations and meteorological variables are given in table 1 .
HEALTH DATA

Anonymous death certificate data for the years 1980-89 were provided from the municipal statistics department. Causes of death were coded locally following the International Classification of Diseases (ICD) codes. Only residents of the city who died within the city were included in the analysis. During the study period, the mean number of daily deaths, excluding deaths from external causes (ICD-9:>799), was 31.9 . Of these, an average of 2.9 deaths/ day were from respiratory causes (ICD-9:460519). These deaths are the focus of this manuscript.

Hospital discharge records from all public and private hospitals for the entire region are routinary collected by the epidemiology department of Lombardia Region. Diagnoses were locally coded to ICD-8 codes up to year 1984, and to ICD-9 codes thereafter. This analysis was restricted to residents of Milan who were admitted to hospital in Milan, or to hospitals in the neighbouring local health units. This represents $92 \%$ of the admissions of Milan citizens during the period. An average of 11.3 admissions per day for respiratory disease occurred in residents aged 15-64 and an average of 8.8 hospital admissions for respiratory disease in older residents.

\section{STATISTICAL METHODS}

Mortality and morbidity were modelled using the APHEA protocol. Poisson regression analysis was used to model dependence of the daily count of deaths or admissions on weather and air pollution, after control for long term trend and season. Long term trend was modelled using dummy variables for years of study, a linear time trend term, and trigonometric functions of time, up to the 6 th order, chosen to remove all significant patterns that were detected by spectral analysis. Because some

Table 1 Distribution of daily data on health indicators, meteorology, and air pollution - Milan, 1980-89.

\begin{tabular}{|c|c|c|c|c|c|c|c|c|c|c|}
\hline & \multirow[t]{2}{*}{ Period } & \multirow[t]{2}{*}{ Mean } & \multirow[t]{2}{*}{ Minimum } & \multicolumn{6}{|l|}{ Centile } & \multirow{2}{*}{$\underset{\%}{\text { Missing* }}$} \\
\hline & & & & 5 th & $25 t h$ & $50 t h$ & 75 th & 95 th & Maximum & \\
\hline \multicolumn{11}{|l|}{ Air pollutants: } \\
\hline \multirow{3}{*}{$\mathrm{SO}_{2}-24 \mathrm{~h}\left(\mu \mathrm{g} / \mathrm{m}^{3}\right)$} & All & $117 \cdot 7$ & $3 \cdot 0$ & $15 \cdot 0$ & $34 \cdot 0$ & $65 \cdot 5$ & $162 \cdot 5$ & $376 \cdot 3$ & $827 \cdot 8$ & $14 \cdot 9$ \\
\hline & Winter & $248 \cdot 6$ & $30 \cdot 6$ & $78 \cdot 8$ & $138 \cdot 5$ & $216 \cdot 0$ & $327 \cdot 8$ & 527.0 & $827 \cdot 8$ & $10 \cdot 1$ \\
\hline & Summer & $30 \cdot 5$ & $3 \cdot 0$ & $9 \cdot 1$ & $18 \cdot 5$ & $27 \cdot 8$ & $39 \cdot 2$ & $62 \cdot 7$ & $113 \cdot 8$ & $20 \cdot 4$ \\
\hline \multirow[t]{3}{*}{$\mathrm{TSP}-24 \mathrm{~h}\left(\mu \mathrm{g} / \mathrm{m}^{3}\right)$} & All & $139 \cdot 0$ & 3.5 & $46 \cdot 5$ & $82 \cdot 0$ & $119 \cdot 5$ & $175 \cdot 7$ & $298 \cdot 5$ & $529 \cdot 5$ & $19 \cdot 0$ \\
\hline & Winter & $193 \cdot 0$ & $33 \cdot 5$ & $77 \cdot 5$ & $128 \cdot 0$ & $174 \cdot 5$ & $246 \cdot 0$ & $355 \cdot 0$ & $529 \cdot 5$ & $12 \cdot 6$ \\
\hline & Summer & $83 \cdot 1$ & $3 \cdot 5$ & $33 \cdot 1$ & $58 \cdot 2$ & $81 \cdot 3$ & $105 \cdot 5$ & 142.5 & $201 \cdot 5$ & $31 \cdot 5$ \\
\hline \multicolumn{11}{|l|}{ Meteorological variables: } \\
\hline \multirow[t]{3}{*}{ Temperature $24 \mathrm{~h}\left(\mathrm{C}^{\circ}\right)$} & All & $14 \cdot 0$ & -6 & 2 & 7 & 14 & 21 & 26 & 31 & - \\
\hline & Winter & $4 \cdot 3$ & -6 & -1 & 2 & 4 & 6 & 9 & 13 & - \\
\hline & Summer & $23 \cdot 6$ & 11 & 18 & 22 & 24 & 26 & 28 & 31 & - \\
\hline \multirow[t]{3}{*}{$\%$ Relative humidity $-24 \mathrm{~h}$} & & $62 \cdot 0$ & 0 & 34 & 50 & 62 & 75 & 90 & 100 & - \\
\hline & Winter & $67 \cdot 0$ & 6 & 30 & 52 & 69 & 82 & 95 & 100 & - \\
\hline & Summer & $56 \cdot 3$ & 17 & 34 & 48 & 56 & 64 & 77 & 95 & - \\
\hline \multicolumn{11}{|l|}{ Respiratory diseases: } \\
\hline \multirow{3}{*}{ No of deaths } & All & $2 \cdot 2$ & 0 & 0 & 1 & 2 & 3 & 5 & 12 & - \\
\hline & Winter & $2 \cdot 9$ & 0 & 0 & 2 & 3 & 4 & 7 & 10 & - \\
\hline & Summer & $1 \cdot 7$ & 0 & 0 & 1 & 1 & 2 & 4 & 10 & - \\
\hline \multirow[t]{3}{*}{ Hospital admissions age: $15-64$ y } & All & $11 \cdot 3$ & 0 & 3 & 7 & 11 & 15 & 22 & 35 & - \\
\hline & Winter & $11 \cdot 8$ & 0 & 4 & 8 & 11 & 16 & 22 & 33 & - \\
\hline & Summer & $9 \cdot 0$ & 0 & 2 & 5 & 8 & 12 & 19 & 33 & - \\
\hline \multirow[t]{3}{*}{ Hospital admissions age: $65+y$} & All & $8 \cdot 8$ & 0 & 3 & 6 & 8 & 11 & 16 & 27 & - \\
\hline & Winter & $10 \cdot 5$ & 0 & 4 & 8 & 10 & 13 & 18 & 27 & - \\
\hline & Summer & 6.5 & 0 & 2 & 4 & 6 & 8 & 12 & 17 & - \\
\hline
\end{tabular}

Winter $=$ December to February; Summer $=$ June to August

$* \%$ after estimation following the APHEA protocol 
patterns can be aliased to several different frequencies when resolved into trigonometric spectra, plots of residuals of the models after the initial choice of trigonometric terms were examined, and any remaining patterns were dealt with. All diagnosis of long term trends was done in models that did not include air pollution. Other factors included in the models were: a dummy variable for months with influenza epidemics (defined as months when the daily admissions for influenza was twice the winter time average), dummy variables for day of the week, and 10 dummy variables for the major holidays.

Separate regression models were fitted for respiratory mortality and for respiratory hospital admissions. Because of the larger number of repiratory hospital admissions, there were sufficient counts to allow separate regressions by age category. Respiratory hospital admissions for children were not analysed because these were dominated by tonsillitis. The choice of weather model was allowed to vary for different outcomes. Exploratory graphical analysis was used to check for any non-linearities in the association with weather terms. If such effects were seen, they were incorporated in the model.

For respiratory mortality, the model included relative humidity, mean temperature of the day before, and six dummy variables for very hot days. These dummy variables were defined to represent $1^{\circ} \mathrm{C}$ temperature intervals from $24^{\circ} \mathrm{C}$ to $29^{\circ} \mathrm{C}$ and over. This approach was chosen because respiratory mortality increased nonlinearly for very hot days. For hospital admissions of people aged 15-64, no effects of very hot days were seen, and the weather model included relative humidity and the same day's temperature. In people aged 65 or more, the weather model included relative humidity and temperature, and a dummy variable for days $29^{\circ} \mathrm{C}$ and hotter.

Once a baseline model had been developed, we examined the association between air pollution and respiratory outcomes. First, graphical analysis was used to determine whether the air pollution variables should be transformed in the regression analysis. Both $\mathrm{SO}_{2}$ and TSP showed evidence of a curvilinear relationship, with a smaller slope at higher concentrations. Consequently, both pollutants were logarithmically transformed in our regression analyses. Because of the high degree of collinearity between the two pollutants, their associations with respiratory outcomes were assessed in single pollutant models. In sensitivity analyses, we examined the association of each pollutant with respiratory mortality and morbidity after stratification by high versus low concentrations of the other pollutant. High concentrations were defined as those above $100 \mu \mathrm{g} / \mathrm{m}^{3}$. Finally Poisson regression models were fitted, including autoregressive terms of the 1 st order for mortality and morbidity in the older age group, and terms up to the 2 nd order for morbidity in the younger age group. The pollutant effect was tested for the exposure during a single day, the same day, or up to two days before (lags: $0,1,2$ ) and for the cumulative

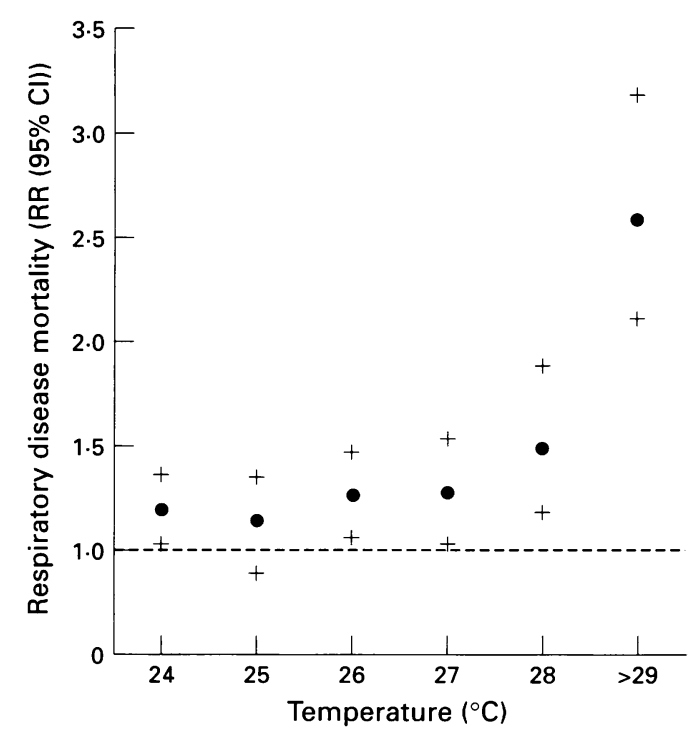

Relative risks, and $95 \%$ confidence intervals for dying of respiratory diseases in relation to ${ }^{\circ} \mathrm{C}$ of temperature over $23^{\circ} \mathrm{C}$. Milan, $1980-89$.

exposure during consecutive days, up to three days before (lags: $0-1,0-2,0-3$ ).

Results from the best fitted models for the single and the cumulative exposure are reported. The pollutants' effect modifications by season were assessed, including in the model a dummy variable for season (reference value: warm season, defined as the semester AprilSeptember) and its interaction term with the pollutant. The relative risks for the pollution results are presented for a $100 \mu \mathrm{g} / \mathrm{m}^{3}$ increase from a concentration of $25 \mu \mathrm{g} / \mathrm{m}^{3}$ to a concentration of $125 \mu \mathrm{g} / \mathrm{m}^{3}$.

It has been observed ${ }^{37}$ that the power of the statistical tests aimed to detect significant interactions may be very low. Given the very high number of observations in this study, we believe that power is not a problem in testing interactions in our analysis.

\section{Results}

WEATHER AND INFLUENZA EPIDEMICS

Hot summer days were associated with an increased risk of deaths when the 24 hour mean temperature reached $24^{\circ} \mathrm{C}(\mathrm{RR}=1 \cdot 20,95 \% \mathrm{Cl}$ $1.04,1.37)$ and the risk increased for each additional degree of temperature. If the temperature was $29^{\circ} \mathrm{C}$ or over the risk reached $2 \cdot 58(95 \% \mathrm{Cl} 2 \cdot 10,3 \cdot 17)$. The figure shows a plot of the relative risks and confidence intervals by degree of temperature above $23^{\circ} \mathrm{C}$. Daily mean temperature of $29^{\circ} \mathrm{C}$ and higher was also associated with an increased risk of respiratory hospital admissions in the older age group $(\mathrm{RR}=1 \cdot 16,95 \% \mathrm{Cl} 1 \cdot 01,1 \cdot 32)$. A significant effect of months with influenza epidemics was found for mortality $(\mathrm{RR}=1 \cdot 15,95 \% \mathrm{Cl} 1.06$, $1.25)$ and hospital admissions in the older age group $\mathrm{RR}=1 \cdot 17(95 \% \mathrm{CL} 1 \cdot 12,22)$.

AIR POLLUTANTS AND MORTALITY DUE TO RESPIRATORY DISEASES

We found a statistically significant positive effect of $\mathrm{SO}_{2}$ exposure on the number of deaths 
Table 2 Hospital admissions for respiratory diseases (ICD-9: 460-519) in the age group 15-64 years. Effects of sulphur dioxide ( $\mathrm{SO}_{2}$ ) and total suspended particulate (TSP) levels $(\mu \mathrm{g} / \mathrm{m} 3)$ log transformed. Autoregressive Poisson models. Milan 1980-89

\begin{tabular}{|c|c|c|c|c|}
\hline Lag & Exposure variable & & $R R^{*}$ & $(95 \% \mathrm{Cl})$ \\
\hline $\begin{array}{l}\mathrm{SO}_{2} \\
0\end{array}$ & $\mathrm{Ln} \mathrm{SO}_{2}$ & & $1 \cdot 05$ & $1 \cdot 00,1 \cdot 10$ \\
\hline 0 & Modification by season $\dagger$ & $\begin{array}{l}\text { Warm } \\
\text { Cool }\end{array}$ & $\begin{array}{l}1 \cdot 04 \\
1 \cdot 06\end{array}$ & $\begin{array}{l}0 \cdot 98,1 \cdot 11 \\
1 \cdot 00,1 \cdot 13\end{array}$ \\
\hline 0 & Modification by TSP levels & $\begin{array}{l}<100 \\
\geq 100\end{array}$ & $\begin{array}{l}1.04 \\
1.03\end{array}$ & $\begin{array}{l}0 \cdot 95,1 \cdot 14 \\
0 \cdot 97,1 \cdot 09\end{array}$ \\
\hline $0-3$ & $\mathrm{Ln} \mathrm{SO}_{2}$ & & 1.09 & $1 \cdot 01,1 \cdot 17$ \\
\hline $0-3$ & Modification by season $\dagger$ & $\begin{array}{l}\text { Warm } \\
\text { Cool }\end{array}$ & $\begin{array}{l}1 \cdot 05 \\
1 \cdot 12\end{array}$ & $\begin{array}{l}0 \cdot 95,1 \cdot 16 \\
1 \cdot 03,1 \cdot 22\end{array}$ \\
\hline $\begin{array}{l}\text { TSP: } \\
2\end{array}$ & Ln TSP & & $1 \cdot 05$ & $1 \cdot 00,1 \cdot 10$ \\
\hline 2 & Modification by season $\dagger$ & $\begin{array}{l}\text { Warm } \\
\text { Cool }\end{array}$ & $\begin{array}{l}1.08 \\
1.02\end{array}$ & $\begin{array}{l}1 \cdot 00,1 \cdot 17 \\
0 \cdot 96,1 \cdot 09\end{array}$ \\
\hline 2 & Modification by $\mathrm{SO}_{2}$ levels & $\begin{array}{l}<100 \\
\geq 100\end{array}$ & $\begin{array}{l}1.04 \\
1.04\end{array}$ & $\begin{array}{l}0 \cdot 97,1 \cdot 12 \\
0 \cdot 97,1 \cdot 12\end{array}$ \\
\hline $0-3$ & Ln TSP & & 1.05 & $0 \cdot 98,1 \cdot 13$ \\
\hline $0-3$ & Modification by season $\dagger$ & $\begin{array}{l}\text { Warm } \\
\text { Cool }\end{array}$ & $\begin{array}{l}1 \cdot 10 \\
1.03\end{array}$ & $\begin{array}{l}0 \cdot 98,1 \cdot 23 \\
0 \cdot 94,1 \cdot 12\end{array}$ \\
\hline
\end{tabular}

${ }^{*} \mathrm{RR}=$ relative risk at $125 \mu \mathrm{g} / \mathrm{m}^{3} v 25 \mu \mathrm{g} / \mathrm{m}^{2} ;+$ Warm season = April-September

Table 3 Hospital admissions for respiratory diseases (ICD-9: 460-519) in the age group over 64 years. Effects of sulphur dioxide ( $\mathrm{SO}_{2}$ ) and total suspended particulates (TSP) levels $\left(\mu \mathrm{g} / \mathrm{m}^{3}\right)$ log transformed. Autoregressive Poisson models. Milan 1980-89

\begin{tabular}{|c|c|c|c|c|}
\hline Lag & Exposure variable & & $R R^{*}$ & $(95 \% \mathrm{Cl})$ \\
\hline $\begin{array}{l}\mathrm{SO}_{2}: \\
0\end{array}$ & $\mathrm{Ln} \mathrm{SO} \mathrm{SO}_{2}$ & & $1 \cdot 04$ & $1 \cdot 00,1 \cdot 09$ \\
\hline 0 & Modification by season $\dagger$ & $\begin{array}{l}\text { Warm } \\
\text { Cool }\end{array}$ & $\begin{array}{l}1.02 \\
1.05\end{array}$ & $\begin{array}{l}0 \cdot 96,1 \cdot 08 \\
1 \cdot 00,1 \cdot 11\end{array}$ \\
\hline 0 & Modification by TSP levels & $\begin{array}{l}<100 \\
\geq 100\end{array}$ & $\begin{array}{l}1.02 \\
1.05\end{array}$ & $\begin{array}{l}0.95,1 \cdot 09 \\
1 \cdot 00,1 \cdot 11\end{array}$ \\
\hline $0-3$ & $\mathrm{Ln} \mathrm{SO}_{2}$ & & $1 \cdot 07$ & $0 \cdot 99,1 \cdot 15$ \\
\hline $0-3$ & Modification by season $¥ \ddagger$ & $\begin{array}{l}\text { Warm } \\
\text { Cool }\end{array}$ & $\begin{array}{l}1.00 \\
1.09\end{array}$ & $\begin{array}{l}0.91,1 \cdot 11 \\
1 \cdot 01,1 \cdot 19\end{array}$ \\
\hline $\begin{array}{l}\text { TSP: } \\
1\end{array}$ & Ln TSP & & $1 \cdot 05$ & $0 \cdot 99,1 \cdot 10$ \\
\hline 1 & Modification by season $f \delta$ & $\begin{array}{l}\text { Warm } \\
\text { Cool }\end{array}$ & $\begin{array}{l}1.00 \\
1.07\end{array}$ & $\begin{array}{l}0 \cdot 92,1 \cdot 08 \\
1 \cdot 01,1 \cdot 14\end{array}$ \\
\hline 1 & Modification by $\mathrm{SO}_{2}$ levels $₫$ & $\begin{array}{l}<100 \\
\geq 100\end{array}$ & $\begin{array}{l}1.02 \\
1.09\end{array}$ & $\begin{array}{l}0.95,1 \cdot 10 \\
1 \cdot 02,1 \cdot 18\end{array}$ \\
\hline $0-1$ & Ln TSP & & 1.05 & $0 \cdot 99,1 \cdot 12$ \\
\hline $0-1$ & Modification by season $t$ & $\begin{array}{l}\text { Warm } \\
\text { Cool }\end{array}$ & $\begin{array}{l}0.99 \\
1.07\end{array}$ & $\begin{array}{l}0 \cdot 90,1 \cdot 10 \\
1 \cdot 00,1 \cdot 15\end{array}$ \\
\hline
\end{tabular}

${ }^{*} \mathrm{RR}=$ relative risk at $125 \mu \mathrm{g} / \mathrm{m}^{3} v 25 \mu \mathrm{g} / \mathrm{m}^{3} ;$ + Warm season $=$ April-September; $\ddagger$ Interaction term at $\mathrm{p}<0 \cdot 10 ; \S$ Interaction term at $\mathrm{p}<0 \cdot 15$
$95 \% \mathrm{Cl} 1.02,1.27)$, but again there was no improvement in fit versus the one day exposure variable. For cumulative exposure, the interaction term with season was significant $(p<0.05)$ and showed a stronger effect of particles in the warm season $(\mathrm{RR}=1.39 ; 95 \% \mathrm{Cl}$ $1.15,1.67)$ than in the cool season. There was no significant difference in the TSP association between low and high $\mathrm{SO}_{2}$ days, but the effect estimate was larger during days with low $\mathrm{SO}_{2}$.

\section{AIR POLLUTANTS AND HOSPITAL ADMISSIONS} FOR RESPIRATORY DISEASES

Tables 2 and 3 show the results observed for hospital admissions. In those aged between 15 and 64 years the best fitting model for the 24 hour $\mathrm{SO}_{2}$ exposure (table 2) was the same day (lag 0), while for the cumulative exposure it was the average of four consecutive days (lag $0-3)$. The effect of $\mathrm{SO}_{2}$ exposure, of the single day or the cumulative days, was more pronounced in the cool months, although the interaction term testing the seasonal difference was not significant. No evidence of interaction with different levels of TSP was found. The best fit in the TSP exposure models (table 2) were obtained with the concentration of two days before (lag 2) and the average of four consecutive days (lag $0-3$ ). The TSP exposure of two days before showed a higher effect in the warm season $(\mathrm{RR}=1 \cdot 08,95 \% \mathrm{Cl} 1.00,1 \cdot 17)$, although the interaction term was not significant. There was no evidence of an interaction with $\mathrm{SO}_{2}$ levels.

In the older age group, the best fit in the models for $\mathrm{SO}_{2}$ exposure (table 3) was found at the same lags as the younger group. The associations were slightly weaker, however. Again, there was a suggestion that the effect was primarily during the cool months, although the interaction term was marginally significant only for the cumulative days exposure $(p<0$, 10). In the analyses of TSP effects on the elderly (table 3), the best fitted models were the previous day (lag 1) and the average of the same and previous day (lag $0-1$ ). TSP air concentrations also seemed to have a greater effect in the cooler months. There was a little evidence of an interaction with $\mathrm{SO}_{2}$ levels over $100 \mu \mathrm{g} / \mathrm{m}^{3}$. $95 \% \mathrm{Cl} 1.03,1.23)$. The interaction term testing whether there was a seasonal difference in the association was not significant $(p=0 \cdot 84)$. The average exposure to $\mathrm{SO}_{2}$ on the same and the previous day had a slightly larger effect size $(\mathrm{RR}=1 \cdot 16,95 \% \mathrm{Cl} 1 \cdot 05,1 \cdot 29)$; this was due to the smaller variance of the two day average pollution measures, and did not reflect any noticeable improvement in model fit. No relevant difference has been observed in the $\mathrm{SO}_{2}$ effect when the level of particulate matters air concentration is below or over $100 \mu \mathrm{g} / \mathrm{m}^{3}$.

TSP was also associated with an increased risk of respiratory mortality $(\mathrm{RR}=1 \cdot 12,95 \% \mathrm{Cl}$ $1.02,1.23)$. The seasonal interaction term was marginally significant $(\mathrm{p}<0 \cdot 10)$, suggesting a trend toward a stronger TSP effect in the warm season. The average TSP exposure over the same and previous day was also associated with an increased respiratory mortality $(R R=1 \cdot 14$,

\section{Discussion}

We found that both $\mathrm{SO}_{2}$ and TSP concentrations were associated with increased risks of respiratory deaths and hospital admissions. This confirms earlier findings. Dockery and Pope $^{12}$ summarised published reports. After converting their $\mathrm{PM}_{10}$ unit into a TSP unit, was associated with a relative risk of 1.17 for respiratory deaths. In this study, we found a relative risk of 1.12 which is quite consistent with their results.

We found an increase of $4-5 \%$ in hospital admissions for all respiratory causes for a $100 \mu \mathrm{g} / \mathrm{m}^{3}$ increase in the TSP or $\mathrm{SO}_{2}$ concentration. This is consistent with the effect, reported in the same review ${ }^{12}$ : combining resthey found that a $100 \mu \mathrm{g} / \mathrm{m}^{3}$ increase in TSP 
ults from different studies the authors found that a $100 \mu \mathrm{g} / \mathrm{m}^{3}$ increase in TSP was associated with a $4 \%$ increase in general hospital admissions for respiratory diseases. These results are also in the range of other estimates reported in a recent review. ${ }^{13}$ Hospital admissions depend on cultural differences and national medical practices, as well as on health status. This can have substantial effects on the baseline number of admissions, and hence on the estimated relative increase. This may affect our findings.

For $\mathrm{SO}_{2}$ the mortality association showed no effect in relation to season, but there was some evidence of such effect for hospital admission; the association seemed stronger in the winter. However, this may merely reflect the fact that non-urgent respiratory admissions form a larger percentage of total respiratory admissions in the warm months when infectious respiratory illness is at a minimum. The particulate matter association showed relatively immediate effects on the number of deaths and hospital admissions in elderly people, for both the single day and the cumulative days exposure (lag 0 or lag 1, and lag 0-1), while the effects were less immediate on hospital admissions in people aged between 15 and 64 years (lag 2 and lag $0-3)$. While some evidence of seasonal interaction for the TSP effects was also seen, this was inconsistent between mortality and hospital admissions. This suggests that the difference could be due to chance. The weak interactions with $\mathrm{SO}_{2}$ seen for TSP exposure are indistinguishable from the seasonal ones. For mortality, the TSP effect was higher in the warm weather and on the days when $\mathrm{SO}_{2}$ was low. For hospital admissions in the elderly the TSP effect was higher in the cool season and for high $\mathrm{SO}_{2}$ days. However, $\mathrm{SO}_{2}$ concentrations are highly seasonal, peaking in the winter, so it is difficult to determine whether these results hint at effect modification by season or $\mathrm{SO}_{2}$, or, given their inconsistency, nothing.

1 Firket J. The cause of the symptoms found in Meuse Valley during the fog of December, 1930. Bulletin de l'Academie Royale de Médecine Belgique 1931;11:683-741.

2 Shrenk HH, Heimann H, Clayton GD, Gafafer WM, Wexler H. Air pollution in Donora PA: Epidemiology of the unusual smog episode of October 1948. Washington DC Public Health Sevice, 1949. Preliminary Report Public Health Bulletin Sevice, 1949.

3 Her Majesty's Public Health Service. Mortality and morbidity during the London fog of December 1952. Report No. 95 on Public Health and Medical Subjects.

4 Fairley D. The relationship of daily mortality to suspended particulates in Santa Clara County. 1980-86. Environ Health Perspect 1990;89:159-68.

5 Kinney PL, Ózkaynak H. Association of daily mortality and air pollution in Los Angeles County. Environ Res 1991; 54:99-120.

6 Schwartz J. Particulate air pollution and daily mortality in Detroit. Environ Res 1991;56:204-13.

7 Schwartz J. Dockery DW. Increased mortality in Philadelphia associated with daily air pollution concentration. Am Rev Respir Dis 1992;145:600-4.
8 Pope CA, Schwartz J, Ransom M. Daily mortality and $\mathrm{PM}_{10}$ pollution in Utah Valley. Arch Environ Health 1992;42: pollution

9 Dockery DW, Schwartz J, Spengler JD. Air pollution and daily mortality: associations with particulates and acid aerosols. Environ Res 1992;59:362-73.

10 Schwartz J. Air pollution and daily mortality in Birmingham, Alabama. Am F Epidemiol 1993;137:1136-47.

11 Schwartz J. Total suspended particulate matter and daily mortality in Cincinnati, Ohio. Environ Health Perspect 1994;102:186-9.

12 Dockery DW, Pope CA. Acute respiratory effects of particulate air pollution. Annu Rev Public Health 1994;15: 107-32.

13 Pope CA, Bates DV, Raizenne ME. Health effects of particulate air pollution: time for reassessment? Environ Health Perspects 1995;103:472-80.

14 Hatzakis A, Katsouyanni K, Kalandidi A, Day N, Tricopoulos D. Short-term effects of air pollution on mortality copoulos D. Short-term effects of air pollution

15 Toulomi G, Pocock SJ, Katsouyanni K, Trichopoulos D. Short-term effect of air pollution on daily mortality in Athens: a time series analysis. Int $\mathcal{f}$ Epidemiol 1994;23: 957-67.

16 Derriennic F, Richardson S, Mollie A, Lellouch J. Shortterm effects of sulphur dioxide pollution on mortality in French cities. Int $\mathcal{F}$ Epidemiol 1989;18:186-97.

17 Schwartz J, Marcus A. Mortality and air pollution in London: a time series analysis. Am f Epidemiol 1990;131: 185-94.

18 Schwartz J, Spix C, Wichmann HE, Malin E. Air pollution and acute respiratory illness in five German communities. Environ Res 1991;56:1-14.

19 Spix C, Heinrich J, Dockery D, Schwartz J, Völksch G, et al. Air pollution and daily mortality in Erfurt, East Germany, 1980-1989. Environ Health Perspect 1993;101:518-26.

20 Mackenmbach JP, Looman CWN, Kunst AE. Air pollution, lagged effect of temperature and mortality: The Nethlagged effect of temperature and mortality: The Neth$21-6$.

21 Saldiva PHN, Pope CA, Schwartz J, et al. Air pollution and mortality in elderly people: a time series study in São Paolo, Brazil. Arch Environ Health 1995;50:159-63.

$22 \mathrm{Xu} \mathrm{X}$, Gao J, Dockery D, Chen Y. Air pollution and daily mortality in residential areas of Beijing, China. Arch Environ Health 1994;49:216-22.

23 Bates DV, Szito R: Hospital admission and air pollutants in Southern Ontario: the acid summer haze effect. Environ Res 1987;43:317-31.

24 Thurston GD, Ito K, Kinney PL, Lippmann M: A multiyear study of air pollution and respiratory hospital admissions in three New York State metropolitan areas results for 1988 and 1989 summers. Fournal of Exposure Analysis and Environmental Epidemiology 1992;2:429-50.

25 Schwartz J, Koeing J, Slater D, Larson T. Particulate air pollution and hospital emergency visits for asthma in Seattle. Am Rev Respir Dis 1993;147:826-31.

26 Burnett RT, Dales RE, Raizenne ME, et al. Effects of low ambient levels of ozone and sulfates on the frequency of respiratory admissions to Ontario hospitals. Environ Res 1994;65:172-94.

27 Schwartz J. Air pollution and hospital admission for the elderly in Birmingham AL. Am f Epidemiol 1994;139. 589-90.

28 Schwartz J. Air pollution and hospital admissions for elderly in Detroit, MI. Am F Respir Crit Care Med 1994;150: 648-55.

29 Schwartz J. Air pollution and hospital admissions for elderly in Minneapolis. Arch Environ Health 1994;49:366-74.

30 Schwartz J. Short term fluctuations in air pollution and hospital admissions of the elderly for respiratory disease. Thorax 1995;50:531-38.

31 Schwartz J. Air pollution and hospital admissions for respiratory disease. Epidemiology 1996;7:20-28.

32 Sunyer J, Antó JM, Murillo C, Saez M. Effects of Urban air pollution on Emergency room admission for chronic air pollution on Emergency room admission for chronic 277-89.

33 Ponka A. Asthma and low levels of air pollution in Helsinki. Arch Envirn Health 1990;46:90-7.

34 Sunyer J, Saez M, Murillo C, Castellsague J, Martinez F, Antó JM. Air pollution and emergency room admissions for chronic obstructive pulmonary diseases: a 5-year study. for chronic obstructive pulmonary

35 Katsouyanni K, Zmirou D, Spix C, et al. Short-term effects of air pollution on health: a European approach using epidemiologic time-series data. The APHEA project: background, objectives, design. Eur Respir $\mathcal{F}$ 1995;81030 38

36 Vigotti MA, Rossi G, Zanobetti A, et al. Inquinamento atmosferico e mortalità giornaliera nei residenti a Milano, 1980-89. Risultati preliminari. Epidemiol Prev 1995;19: $85-9$

37 Greenland S. Tests for interaction in epidemiologic studies: a review and a study of power. Stat Med 1983;2:243-51. 